\title{
Robust high-throughput assays to assess discrete steps in ubiquitination and related cascades
}

\author{
Gabriel Fenteany ${ }^{1 * \dagger}$, Paras Gaur ${ }^{1,2+}$, Gaurav Sharma ${ }^{1,2}$, Lajos Pintér $^{3}$, Ernő Kiss ${ }^{1}$ and Lajos Haracska ${ }^{1 *}$
}

\begin{abstract}
Background: Ubiquitination and ubiquitin-like protein post-translational modifications play an enormous number of roles in cellular processes. These modifications are constituted of multistep reaction cascades. Readily implementable and robust methods to evaluate each step of the overall process, while presently limited, are critical to the understanding and modulation of the reaction sequence at any desired level, both in terms of basic research and potential therapeutic drug discovery and development.
\end{abstract}

Results: We developed multiple robust and reliable high-throughput assays to interrogate each of the sequential discrete steps in the reaction cascade leading to protein ubiquitination. As models for the E1 ubiquitin-activating enzyme, the E2 ubiquitin-conjugating enzyme, the E3 ubiquitin ligase, and their ultimate substrate of ubiquitination in a cascade, we examined Uba1, Rad6, Rad18, and proliferating cell nuclear antigen (PCNA), respectively, in reconstituted systems. Identification of inhibitors of this pathway holds promise in cancer therapy since PCNA ubiquitination plays a central role in DNA damage tolerance and resulting mutagenesis. The luminescence-based assays we developed allow for the quantitative determination of the degree of formation of ubiquitin thioester conjugate intermediates with both E1 and E2 proteins, autoubiquitination of the E3 protein involved, and ubiquitination of the final substrate. Thus, all covalent adducts along the cascade can be individually probed. We tested previously identified inhibitors of this ubiquitination cascade, finding generally good correspondence between compound potency trends determined by more traditional lowthroughput methods and the present high-throughput ones.

Conclusions: These approaches are readily adaptable to other E1, E2, and E3 systems, and their substrates in both ubiquitination and ubiquitin-like post-translational modification cascades.

Keywords: Ubiquitination, Ubiquitin-like proteins, Post-translational modifications, E1 ubiquitin-conjugating enzymes, E2 ubiquitin-conjugating enzymes, E3 ubiquitin ligases, Step-specific assays and evaluation, High-throughput screening

\footnotetext{
* Correspondence: fenteany.gabriel@brc.hu; haracska.lajos@brc.hu

${ }^{+}$Gabriel Fenteany and Paras Gaur contributed equally to this work.

${ }^{1}$ HCEMM-BRC Mutagenesis and Carcinogenesis Research Group, Institute of

Genetics, Biological Research Centre, Szeged, Temesvári krt. 62, Szeged 6726, Hungary

Full list of author information is available at the end of the article
}

(c) The Author(s). 2020 Open Access This article is licensed under a Creative Commons Attribution 4.0 International License, which permits use, sharing, adaptation, distribution and reproduction in any medium or format, as long as you give appropriate credit to the original author(s) and the source, provide a link to the Creative Commons licence, and indicate if changes were made. The images or other third party material in this article are included in the article's Creative Commons licence, unless indicated otherwise in a credit line to the material. If material is not included in the article's Creative Commons licence and your intended use is not permitted by statutory regulation or exceeds the permitted use, you will need to obtain permission directly from the copyright holder. To view a copy of this licence, visit http://creativecommons.org/licenses/by/4.0/ The Creative Commons Public Domain Dedication waiver (http://creativecommons.org/publicdomain/zero/1.0/) applies to the data made available in this article, unless otherwise stated in a credit line to the data. 


\section{Background}

Post-translational modification of proteins through ubiquitination controls not only protein degradation by the proteasome but also myriad other processes. Ubiquitin and related ubiquitin-like proteins (UBLs) serve as tags and docking sites for protein-protein interactions that regulate a staggering array of biological pathways. Modulating various steps of ubiquitination and UBL post-translational modification pathways with smallmolecule inhibitors or activators/enhancers has considerable research and therapeutic potential. One such function for ubiquitin and UBLs is in the dynamic control of the DNA damage repair and tolerance machinery. DNA damage tolerance pathways evolved to circumvent the fact that DNA sites altered by chemical insult, oxidation, photodamage, or irradiation that have not been repaired by other DNA repair mechanisms (such as base and nucleotide excision or mismatch repair) cause the stalling of the DNA replication fork. Replicative DNA polymerases are unable to copy damaged DNA. There are two general pathways of DNA damage tolerance: translesion DNA synthesis (TLS) and template switching. However, TLS is inherently prone to introducing point mutations, whereas template switching can result in chromosomal rearrangements. DNA damage tolerance can thus lead to genetic alterations, oncogenesis, formation of secondary tumors after treatment with DNA-damaging therapeutics, drug resistance, and other pathologies, with strong evidence that inhibition of the DNA damage response can lead to reversal of drug resistance in and apoptotic death of a range of different cancer cell types (reviewed in refs. [1-6]).

The ubiquitination of proliferating cell nuclear antigen (PCNA), a sliding clamp complex critical to DNA replication and repair, on a specific lysine residue (K164) is a key step in the activation of the DNA damage tolerance pathways. PCNA forms a homotrimeric ring encircling DNA, binding and coordinating the activities of a broad range of proteins, including DNA polymerases and many replication, repair, and regulatory factors (reviewed in refs. [7-11]). Monoubiquitination of PCNA triggers the TLS pathway, whereas further polyubiquitination of this ubiquitin moiety (linked to ubiquitin's K63 residue, rather than the K48 involved in proteasomal degradation) involves additional factors and initiates the alternative pathway of template switching. Once loaded onto DNA, an ATP-dependent process facilitated by replication factor C (RFC), PCNA becomes capable of being monoubiquitinated on $\mathrm{K} 164$ by the E2 ubiquitin-conjugating enzyme Rad6 in complex with the E3 ubiquitin ligase Rad18, the former being the catalyst and the latter the adaptor for specific substrate recognition. The ubiquitination reaction cascade begins with the activation of the carboxy terminus of ubiquitin, catalyzed by the E1 ubiquitin-activating enzyme Uba1 (also known as UBE1), through reaction with ATP to form a ubiquitin adenylate intermediate, with subsequent steps not requiring ATP. The ubiquitin adenylate, still bound to Uba1, then reacts with a catalytic cysteine residue on Uba1, resulting in a Uba1 ubiquitin thioester conjugate. The ubiquitin is subsequently transferred to Rad6 to generate a Rad6 ubiquitin thioester conjugate. In complex with Rad18, the thioester then reacts with the sidechain amine of K164 on PCNA to form a more stable PCNA-ubiquitin isopeptide bond. The Rad6-Rad18 dimer can also autoubiquitinate Rad18 at multiple sites in vitro and in the cell, which appears to affect its function, subcellular localization, and stability [12, 13].

The human genome encodes two ubiquitin-specific E1 enzymes, approximately 40 ubiquitin-specific E2 enzymes, and over 600 ubiquitin-specific E3 proteins, with pathway selectivity narrowing as the sequence proceeds, ultimately involving recognition of a given substrate by a specific E3 protein. The vast majority of E3 ubiquitin ligases, such as Rad18, are of the so-called RING class, functioning as adaptors between a given E2 protein and a specific substrate protein, with transfer of ubiquitin from the E2 protein to the ultimate substrate. There are also two other types of E3 proteins, the HECT and RINGBetween-RING classes, that themselves also form thioester conjugates with ubiquitin, as a third and final level of thioester-forming enzyme to mediate transfer of ubiquitin to the ultimate substrate (reviewed in refs. [14-17]). In addition to ubiquitin-specific E1, E2, and E3 proteins, there are cognate UBL-specific proteins, with some functional overlap between them. There are, therefore, a huge number of potential pathways to probe.

The high-throughput assays we report here to probe the PCNA ubiquitination cascade at different levels are all reconstituted systems, composed of the purified proteins relevant to each specific assay, adapted to the amplified luminescent proximity homogeneous assay (Alpha) system. The Alpha system has various advantages over other proximity-based approaches, such as the enzymelinked immunosorbent assay (ELISA) and resonance energy transfer (RET) methods (e.g. fluorescence resonance energy transfer and bioluminescence resonance energy transfer) in terms of flexibility, adaptability, and sensitivity (reviewed in ref. [18]). Unlike conventional ELISAs, the Alpha system is a solution-phase and homogeneous assay-not requiring wash and separation steps-and has greater sensitivity and wider dynamic range. In comparison to RET methods, an advantage of the Alpha system is that it works without the stringent short distance and orientation restrictions on the donor-acceptor pair. Tagging or labeling two proteins (or other molecules) with any of the many tags or labels recognized by available Alpha bead coatings is generally enough to develop 
a workable Alpha system, without the laborious trialand-error of developing a suitably coupled RET pair system.

We found the high-throughput Alpha assays for the different steps in the PCNA ubiquitination cascade to be robust, reliable, and sensitive. We found half-maximal inhibitory concentration $\left(\mathrm{IC}_{50}\right)$ values and structure-activity relationship trends for Uba1 inhibitors we previously reported [19] as determined by the Alpha assay generally corresponding to other more traditional methods in terms of both inhibition of the overall PCNA ubiquitination cascade and Uba1 specifically. Thus, the system performs well as a screening tool for this reaction sequence and as a legitimate quantitative method for measuring ubiquitination and formation of thioester conjugates. The approaches should be straightforwardly adaptable to other ubiquitination or UBL post-translational modification cascades.

\section{Results}

Overview of study

Starting from conditions we optimized previously for Western blot analysis and quantitation of PCNA ubiquitination, as well as gel-based analyses of the formation of Uba1 ubiquitin thioester and Rad6 ubiquitin thioester conjugates [19], we further refined the reconstituted systems for the more sensitive Alpha technology. We sought to reduce the concentrations of the components in the reactions and also optimize the subsequent detection step of the assays. In the process, we developed a high-throughput Alpha-based PCNA ubiquitination assay that balances high sensitivity with low consumption of reagents, as well as analogous Alpha assays to probe Uba1 ubiquitin thioester formation, Rad6 ubiquitin thioester formation, and Rad18 autoubiquitination (Fig. 1).

Optimization of the Alpha assay for PCNA ubiquitination As a departure point, we began with the conditions we had found provided virtually complete ubiquitination of PCNA readily detectable by Western blot analysis [19]. We individually varied concentrations of FLAG-PCNA (Fig. 2a), biotin-ubiquitin (Fig. 2b), RFC (Fig. 2c), Uba1 (Fig. 2d), and Rad6-Rad18 dimer (Fig. 2e). In each case, we ascertained optimal concentration ranges for strong Alpha signals.

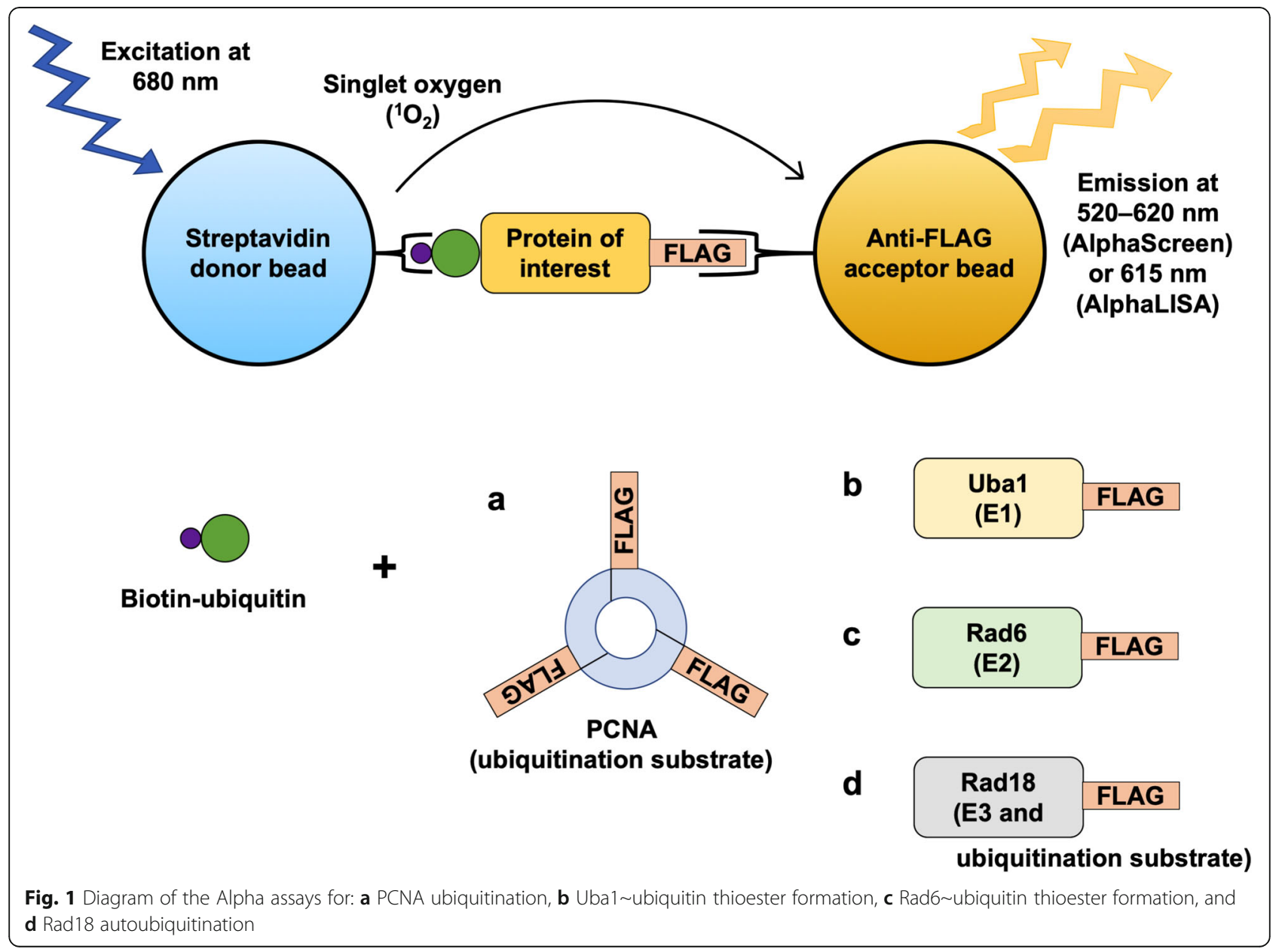


a

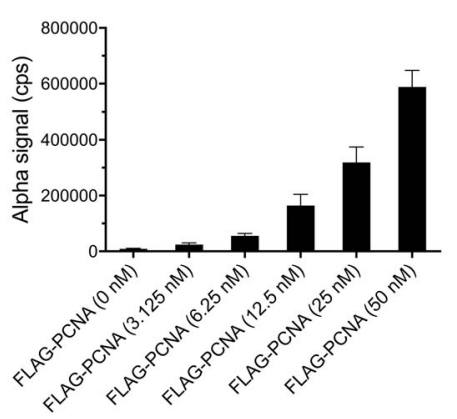

C

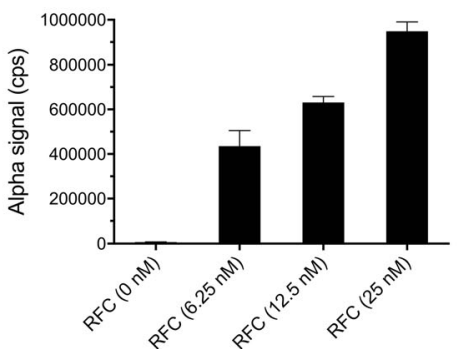

d

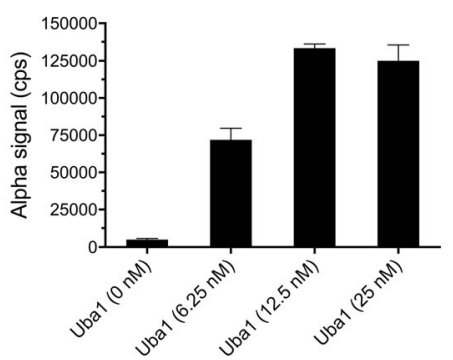

f b

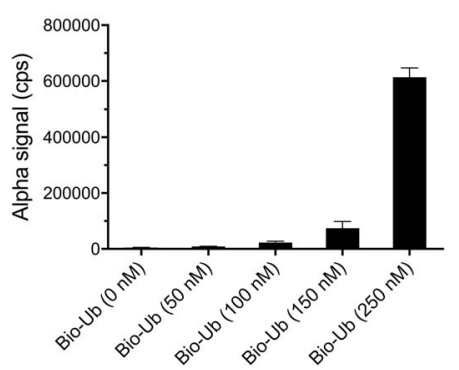

C bis

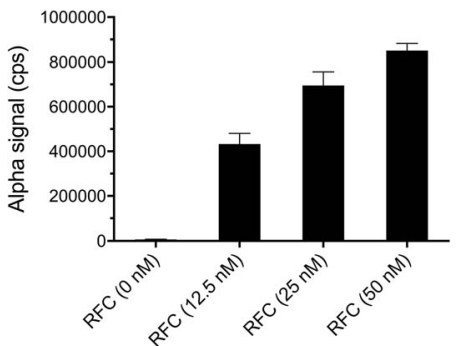

e

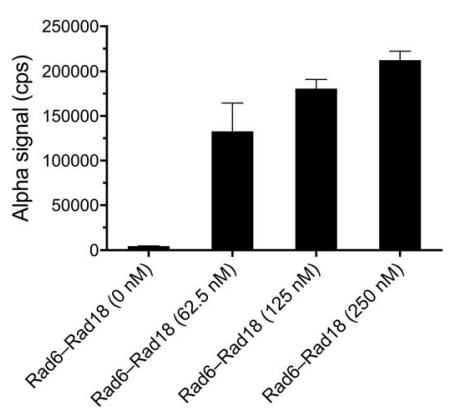

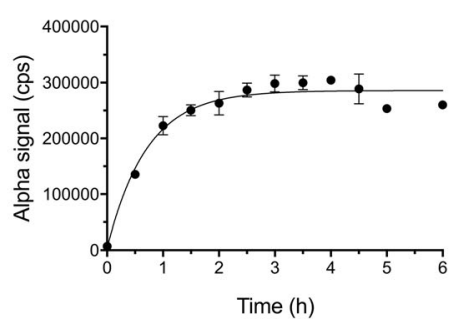

Fig. 2 Alpha assay for PCNA ubiquitination. Data represent mean and standard deviation (SD) for 3-6 replicate samples in each case. Variable concentrations of: a FLAG-PCNA, b biotin-ubiquitin (Bio-Ub), c RFC (left and right panels are different concentration ranges from separate experiments), $\mathbf{d} \cup b a 1$, and e Rad6-Rad18 dimer, with other components in each case held constant as noted in Methods. $\mathbf{f}$ Reaction kinetics under final optimized conditions. Details are described in Methods

To investigate miniaturization questions, we evaluated the reaction done in different volumes (Additional file 1: Fig. S1). We also investigated the optimal parameters for Alpha detection after the PCNA ubiquitination reaction, looking at different dilution factors (Additional file 2: Fig. S2), donor and acceptor bead concentrations (Additional file 3: Fig. S3a), donor and acceptor bead ratios (Additional file 3: Fig. S3b), order of addition of donor and acceptor beads (Additional file 4: Fig. S4), and bead incubation times prior to detection (Additional file 5: Fig. S5). We found best results with $10 \times$ dilution and simultaneous addition of donor and acceptor beads.
In terms of signal, while $20 \mu \mathrm{g} / \mathrm{ml}$ yielded stronger signals, we decided on $10 \mu \mathrm{g} / \mathrm{ml}$ to reduce bead consumption, since it gave good results nonetheless. With regard to incubation time with beads, longer incubations resulted in better signals.

Based on all the preceding experiments on the PCNA ubiquitination reaction and the Alpha detection step of the overall assay, we chose final concentrations, conditions, and procedures that balanced sensitivity and assay quality with the practical concerns of usage of proteins and beads, as described in Methods. Under these adopted conditions, we conducted a kinetics experiment 
to establish the time course of the reaction, with saturation reached around $2 \mathrm{~h}$ at $25^{\circ} \mathrm{C}$ (Fig. 2f).

With protein concentrations for the PCNA ubiquitination cascade and Alpha conditions set, we investigated the dependence of the PCNA ubiquitination cascade on ATP concentration, which appeared to become nonlimiting for an incubation of $2 \mathrm{~h}$ at $25^{\circ} \mathrm{C}$ in the high micromolar range (Additional file 6: Fig. S6a). We also probed dimethyl sulfoxide (DMSO) tolerance of the reaction, as DMSO is the most commonly used carrier solvent for compound delivery in screening (Additional file 6: Fig. S6b).

We found $\mathrm{Z}^{\prime}$ factors had typical values for any given plate of between 0.6 and 0.9 , particularly by robust statistics, which is less sensitive to outliers than standard statistics, when comparing positive (with ATP) and negative (without ATP) control values on each plate, indicating suitability for high-throughput screening. Strictly standardized mean difference values, signal-tonoise ratios, signal-to-background ratios, and signal window values per plate were generally also very good.

\section{Alpha assays for Uba1 ubiquitin, Rad6 ubiquitin, and Rad18 autoubiquitination}

We developed three additional Alpha assays to probe other steps in the PCNA ubiquitination cascade. First, we adapted the Alpha system for quantitative evaluation of Uba1 ubiquitin thioester formation, again starting with the conditions we previously worked out for gel-based detection [19] and then refined for Alpha detection. We used a FLAGUba1 construct and individually varied concentrations of the analytes, FLAG-Uba1 (Fig. 3a), with the decline in signal at higher concentrations the probable result of the hook effect (see Discussion), and biotin-ubiquitin (Fig. 3b), finding conditions yielding good results.

Second, we developed an Alpha assay for detection of the Rad6 ubiquitin thioester conjugate, again starting from conditions previously developed for gel-based detection [19]. We made a FLAG-Rad6 construct and performed reactions with non-FLAG-tagged Ubal and biotin-ubiquitin. We individually varied concentrations of Rad6 (Fig. 3c) and biotin-ubiquitin (Fig. 3d), again defining conditions that gave satisfactory results.

We then split the two-reaction sequence into two steps to allow for more narrow screening for direct Rad6 modulators as distinct from those that secondarily affect Rad6 by instead directly targeting Uba1, with a first step for Uba1 charging with ubiquitin and then a second step where the precharged Uba1 ubiquitin was combined with Rad6 (preincubated with compound in a screening setting) for the transthioesterification reaction (Additional file 7: Fig. S7a). We experimented with adding ethylenediaminetetraacetic acid (EDTA) to the charged Uba1 ubiquitin samples before adding Rad6 to chelate the $\mathrm{Mg}^{2+}$ and prevent further ATP-dependent charging of Ubal with ubiquitin after being mixed with Rad6 so that the assay would be potentially a yet cleaner transthioesterification readout to evaluate Rad6 ubiquitin thioester formation solely. This would mitigate the possibility of picking up false positives from the Rad6 ubiquitin thioester formation assay that bleed over and inhibit Uba1 instead. At a final EDTA concentration of $20 \mathrm{mM}$, the same concentration employed above to terminate the overall PCNA ubiquitination reaction sequence before the Alpha step, we found diminished transthioesterification from Uba1 to Rad6 for some reason, despite being a reaction not requiring $\mathrm{Mg}^{2+}$-ATP (Additional file 7: Fig. S7a). We thus reconfigured the Rad6 ubiquitin thioester formation assay with less ATP $(250 \mu \mathrm{M})$ and $\mathrm{MgCl}_{2}(500 \mu \mathrm{M})$, then varied the concentration of EDTA for quenching Uba1 precharging, with little-to-no effect on the reaction up to $2 \mathrm{mM}$ EDTA (Additional file 7: Fig. S7b). Another option for preventing further Uba1 charging would be adding apyrase to hydrolyze ATP between the steps.

Finally, we developed an Alpha assay for the detection of Rad18 autoubiquitination. We constructed a FLAGRad18 construct and performed reactions with nonFLAG-tagged Uba1, Rad6-Rad18 dimer, and biotinubiquitin. Variation of concentrations of FLAG-Rad18 (Fig. 3e) and biotin-ubiquitin (Fig. 3f) for this reaction was also performed, and we again found conditions that resulted in good outcomes. We then once more implemented a quench of Ubal charging with EDTA, as we did with the Rad6 ubiquitin thioester formation reaction in a split assay (Additional file 7: Fig. S7c), again allowing for elimination of any bleedover effects of compound on Uba1.

In choosing conditions for each assay to use for screening, we balanced the desire to reduce protein concentrations with retaining good signals. Flowcharts for the conditions and procedures for the four Alpha assays (PCNA ubiquitination, Uba1 ubiquitin thioester formation, Rad6 ubiquitin thioester formation, and Rad18 autoubiquitination) are shown in Fig. 4.

\section{Evaluation of the performance of the Alpha assays for PCNA ubiquitination and Uba1 ubiquitin thioester formation by testing with already identified inhibitors}

In addition to evaluating plate quality control metrics, we further validated the assays with inhibitors of Uba1 we recently discovered [19], a number of different green tea compounds (structures in Fig. 5). We performed dose-response experiments with the Alpha assays for PCNA ubiquitination (Fig. 6) and Uba1 ubiquitin thioester formation (Fig. 7a and b). The structure-activity relationships were similar to those we previously reported [19], with generally similar trends in relative calculated 


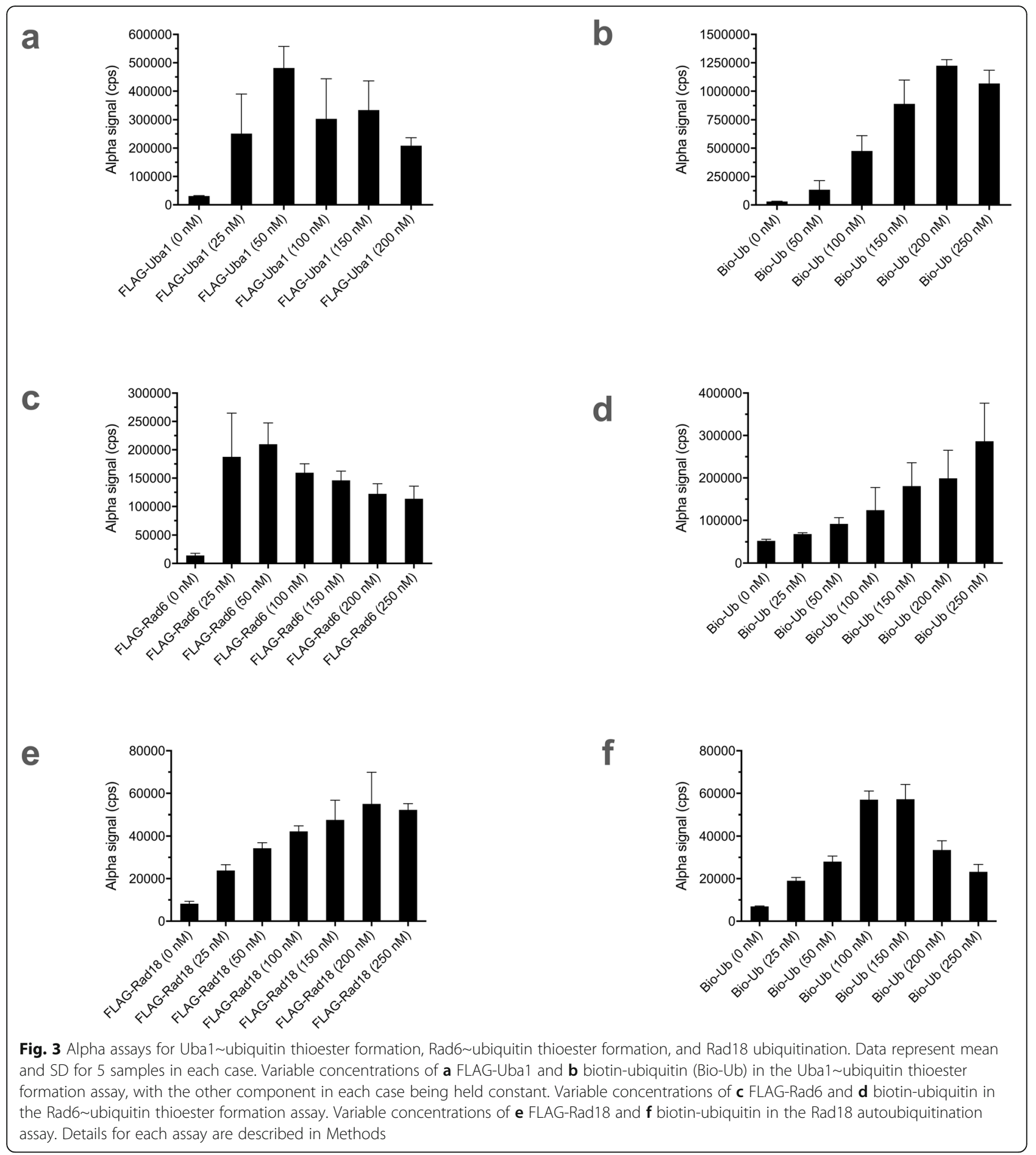

$\mathrm{IC}_{50}$ values for each of the bioactive compounds, as shown in Table 1.

\section{Discussion}

The PerkinElmer Alpha system is based on the luminescent oxygen channeling immunoassay, a homogeneous bead-based immunoassay method. High-energy irradiation at $680 \mathrm{~nm}$ excites the photosensitizer phthalocyanine in the Alpha donor beads, which converts ambient ground-state oxygen to an excited singlet state (distinct from the far more reactive superoxide radical), which has a half-life of $\sim 4 \mu$ s in aqueous solutions and can diffuse over a distance of up to $\sim 200 \mathrm{~nm}$. If an Alpha acceptor bead is within this distance, the singlet 


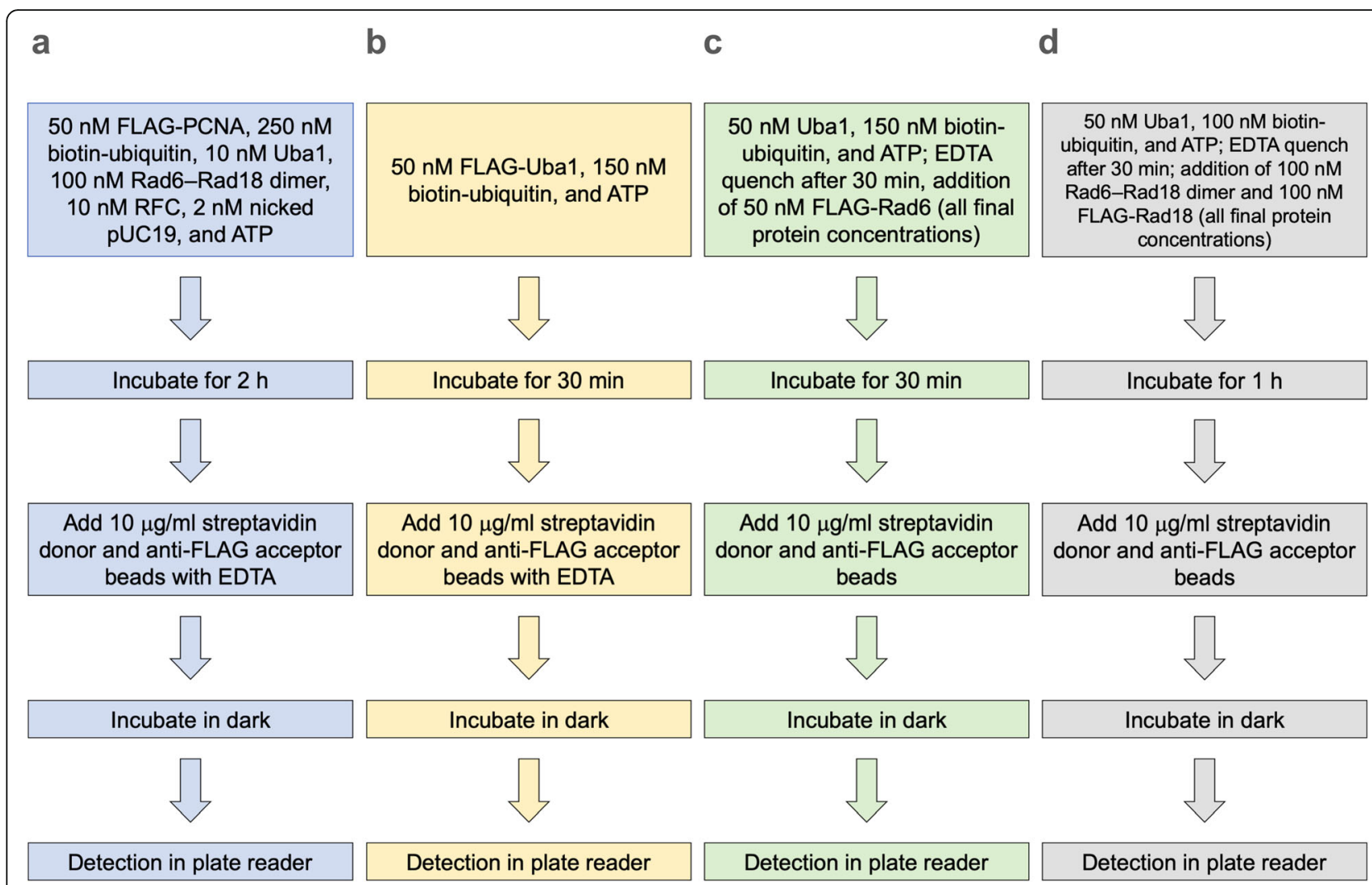

Fig. 4 Flowchart of optimized conditions for each Alpha assay. Stepwise procedures are shown for: a PCNA ubiquitination, b Uba1 ubiquitin thioester formation, $\mathbf{c}$ Rad6 ubiquitin thioester formation, d Rad18 autoubiquitination. Detailed conditions are described in Methods

oxygen can react with a thioxene derivative in the acceptor bead, producing a chemiluminescent emission that excites fluors also contained in the acceptor beads (anthracene and rubrene for the version of the assay known as AlphaScreen or a europium chelate for that known as AlphaLISA). The resulting fluorescent emissions $(520-620 \mathrm{~nm}$ or $615 \mathrm{~nm}$ for AlphaScreen or AlphaLISA, respectively) are detected by a photomultiplier tube. AlphaLISA acceptor beads, with a more narrowly defined and sharp emission spectrum, are useful in certain samples, such as serum or plasma, where there may be components that interfere with the AlphaScreen emission. In the present study, we employed the AlphaScreen acceptor beads, but we have also worked with AlphaLISA acceptor beads in the PCNA ubiquitination assay and found no difference in performance between the two versions of the Alpha assay in our system [19].

We have applied the Alpha system to the PCNA ubiquitination cascade, first to the overall process and then to the different intermediary steps in the reaction sequence involving covalent ubiquitin adducts. Modulators of the different specific components of the PCNA ubiquitination cascade can be identified and characterized in terms of degree of potency readily, allowing for rapid discovery of both potential research probes and therapeutic agents with a broad spectrum of anticancer activity.

In addition to its utility as a high-throughput screening method with advantages over RET and ELISA approaches (reviewed in ref. [18]), the Alpha system is considerably quicker, simpler, and more sensitive than Western blot analysis and other traditional methods for low-throughput detection of ubiquitination or ubiquitin thioester conjugates. We found reasonably good correspondence in compound potency trends between the Alpha assay and traditional assays (Table 1) with the Uba1 inhibitors we previously reported [19]. In addition, the Alpha system has been used to probe components of other ubiquitination or UBL post-translational modification pathways [20-25]. Here we have adapted it to look at new ultimate substrate modifications (PCNA and Rad18) and also to evaluate intermediate ubiquitin conjugates in the pathway. The approach can be employed to screen not only for inhibitors but also for activators/ enhancers of these processes, particularly if the screening is done at reaction times prior to normal attainment of saturating modification of a substrate.

Optimization of protein and bead concentrations and other parameters is important in the implementation of 
<smiles>O=C(O[C@H]1Cc2c(O)cc(O)cc2O[C@H]1c1cc(O)c(O)c(O)c1)c1cc(O)c(O)c(O)c1</smiles>

(-)-Epigallocatechin-3-gallate (EGCG)<smiles>O=C(O[C@H]1Cc2c(O)cc(O)cc2O[C@H]1c1ccc(O)c(O)c1)c1cc(O)c(O)c(O)c1</smiles>

(-)-Epicatechin-3-gallate (ECG)<smiles>Oc1cc(O)c2c(c1)O[C@H](c1cc(O)c(O)c(O)c1)[C@H](O)C2</smiles>

(-)-Epigallocatechin (EGC)<smiles>Oc1cc(O)c2c(c1)O[C@H](c1ccc(O)c(O)c1)[C@H](O)C2</smiles>

(-)-Epicatechin (EC)<smiles>Oc1cc(O)c2c(c1)O[C@H](c1ccc(O)c(O)c1)[C@H](O)C2</smiles>

(+)-Catechin (Cat)<smiles>O=C(O)c1cc(O)c(O)c(O)c1</smiles>

Gallic acid (GA)<smiles>CCOC(=O)c1cc(O)c(O)c(O)c1</smiles>

n-Propyl gallate (PG)<smiles></smiles>

Myricetin (Myr)<smiles>CCOC(=O)c1cc(O)c(O)c(O)c1</smiles>

n-Octyl gallate (OG)<smiles>CCOC(=O)c1cc(O)c(O)c(O)c1</smiles>

n-Dodecyl gallate (DG)

\section{Fig. 5 Structures of Uba1 inhibitors and their analogs examined in the Alpha assays. The compounds, some of which inhibit Uba1 and} ubiquitination, as we previously reported [19], were: (-)-epigallocatechin-3-gallate (EGCG), (-)-epicatechin-3-gallate (ECG), (-)-epigallocatechin (EGC), (-)-epicatechin (EC), (+)-catechin (Cat), gallic acid (GA), n-propyl gallate (PG), n-octyl gallate (OG), n-dodecyl (lauryl) gallate (DG), myricetin (Myr), and (+)-dihydromyricetin (DM)

an Alpha-based screening effort from the standpoints of utilizing economical amounts of proteins and beads while retaining good signal strength and dynamic range.
The overall Alpha assay can be viewed as composed of two main parts: first, the biochemical process of interest that generates the proximity relationship to be 


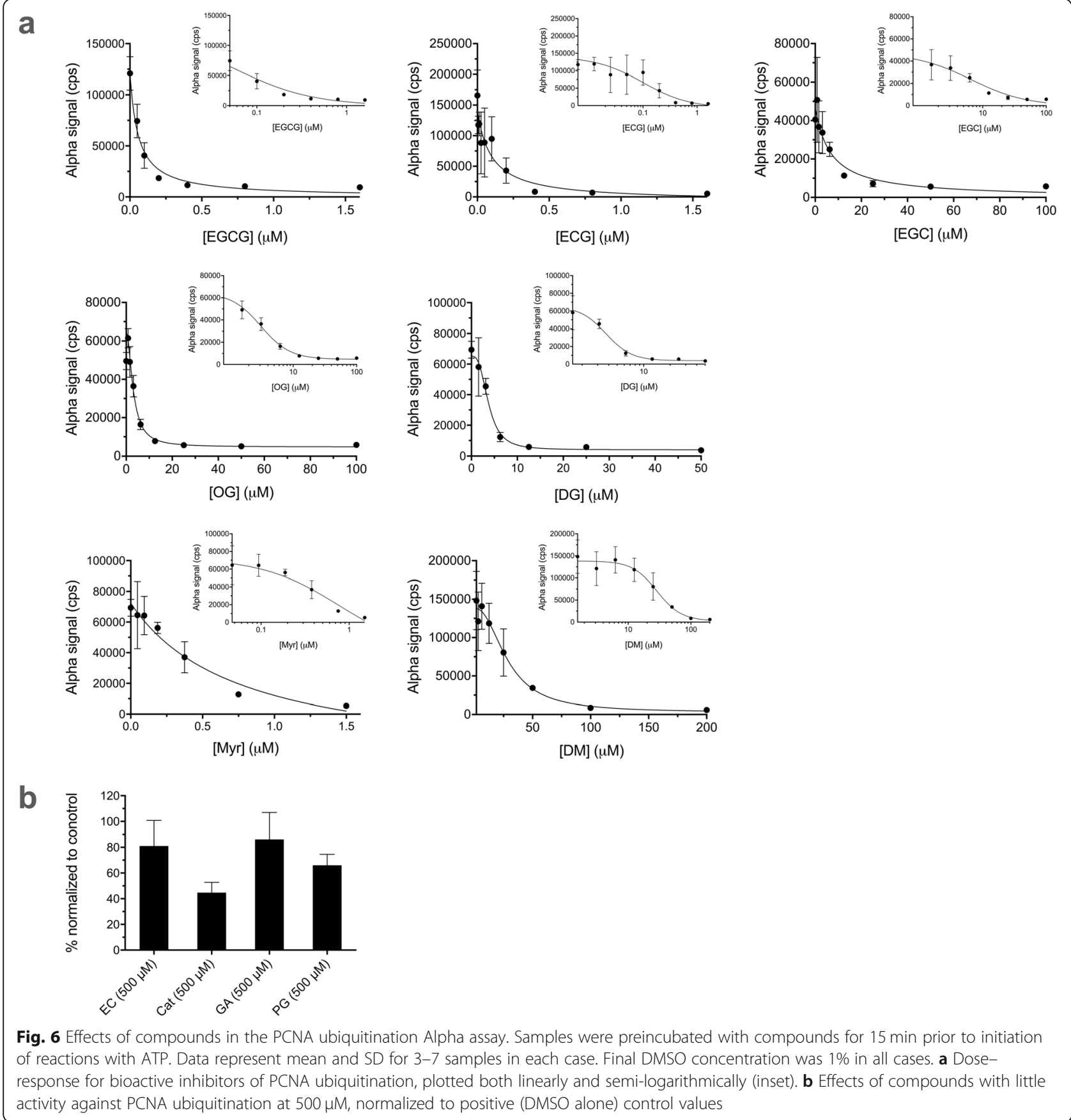

assayed; second, the procedures for Alpha detection (which involves dilution of the initial samples with addition of beads and then the actual detection itself). Both of these major steps of the overall assay must be optimized. We found that while the dynamic signal range was consistently good, graded, and reproducible, precise signal intensity values of the range (e.g. between minimum and maximum signal values or between negative and positive control values) can vary from experiment to experiment, even under ostensibly identical conditions; thus, combining data from multiple independent experiments should be done only after meaningful normalization. Another point to note is that the Alpha assay is susceptible to the high-dose hook effect-wherein too high concentrations of analytes can result in diminished signals in bimolecular detection assays involving saturable reagent binding such as in AlphaScreen/AlphaLISA, ELISA, and indirect-detection (e.g. antibody-based) RET systems-which plays into these considerations. (The hook effect, also referred to 


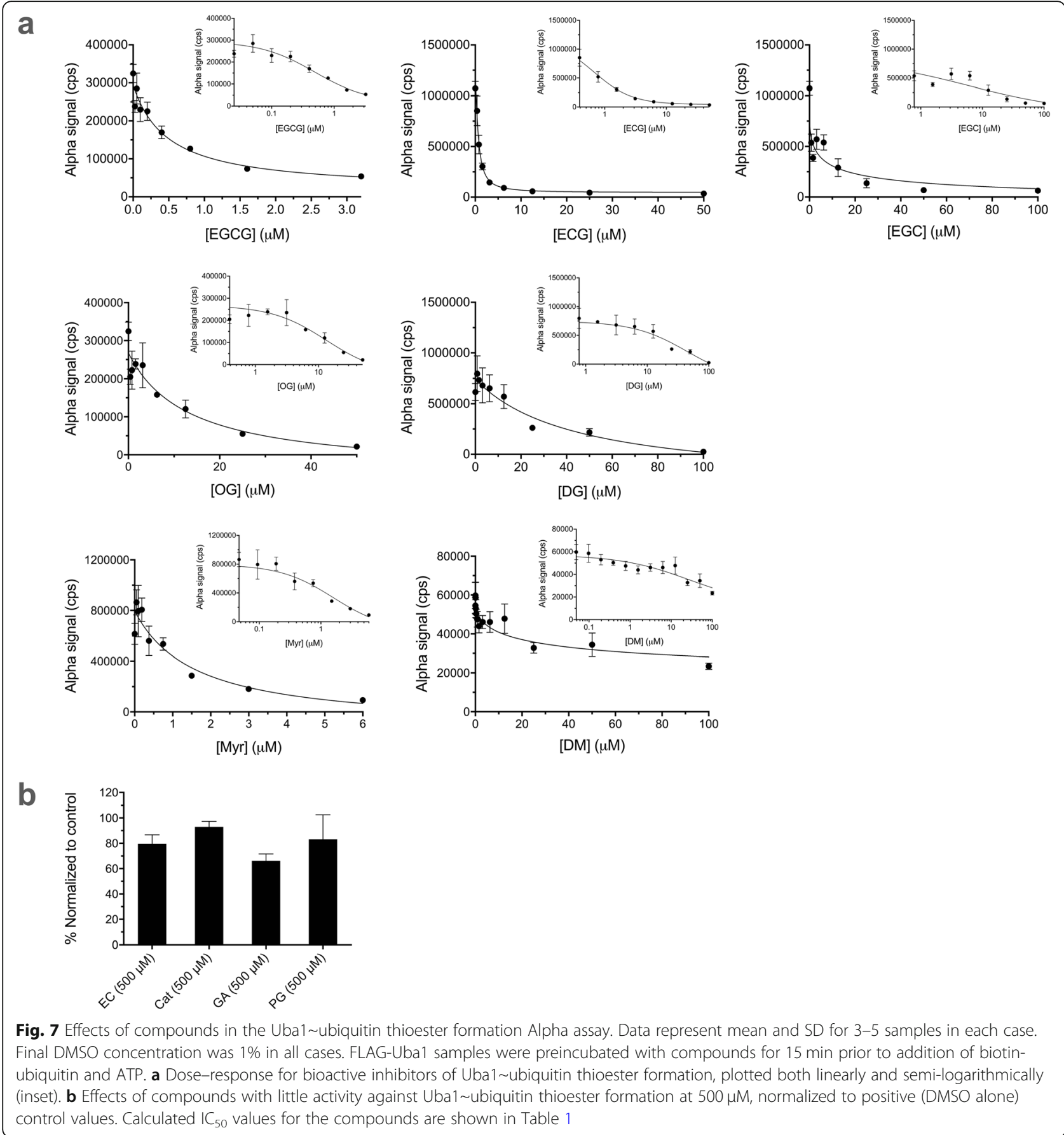

as the hooking or prozone effect, is named after the shape of the analyte concentration-signal curve in such cases, which resembles a fish hook.) Optimal concentrations, conditions, and procedures cannot be predicted a priori for any given experimental system. They will depend on factors such as the nature of the analytes, the analyte-capturing coating on the beads, their affinities, and the stoichiometries of their interactions. Optimal assay parameters must therefore be determined empirically for any given system.

\section{Conclusions}

We have developed and validated multiple assays, based on the powerful Alpha technology, to assess ubiquitination of a substrate protein and the formation of ubiquitin thioester conjugates involved in the reaction cascade. We show that PCNA ubiquitination and the intermediate steps leading to ultimate substrate modification can be interrogated in a high-throughput manner that also directly yields externally verifiable results for valid measures of the potency of inhibitors for discrete steps in 
Table 1 Half-maximal inhibitory concentration $\left(I_{50}\right)$ values for compounds against PCNA ubiquitination and Uba1 ubiquitin thioester formation by the Alpha assay compared to other methods. All IC 50 , standard error (SE), and 95\% confidence interval (Cl) values listed were calculated by nonlinear regression with GraphPad Prism software. Ind. = indeterminate

\begin{tabular}{|c|c|c|c|c|}
\hline Compound & $\begin{array}{l}\mathrm{IC}_{50} \text { for inhibition of PCNA } \\
\text { ubiquitination (Alpha) }\end{array}$ & $\begin{array}{l}\mathrm{IC}_{50} \text { for inhibition of PCNA } \\
\text { ubiquitination } \\
\text { (Western blot) [19] }\end{array}$ & $\begin{array}{l}\mathrm{IC}_{50} \text { for inhibition of Uba1 Ub } \\
\text { thioester formation } \\
\text { (Alpha) }\end{array}$ & $\begin{array}{l}\mathrm{IC}_{50} \text { for inhibition of Uba1 Ub } \\
\text { thioester formation (gel-based) [19] }\end{array}$ \\
\hline EGCG & $\begin{array}{l}0.0566 \mu \mathrm{M}(\mathrm{SE}=0.00954 ; \mathrm{Cl}: \\
0.0409-0.0776)\end{array}$ & $\begin{array}{l}0.228 \mu \mathrm{M}(\mathrm{SE}=0.0342 ; \mathrm{Cl}: \\
0.171-0.319)\end{array}$ & $\begin{array}{l}0.488 \mu \mathrm{M}(\mathrm{SE}=0.145 ; \mathrm{Cl}: \\
0.259-0.949)\end{array}$ & $\begin{array}{l}1.63 \mu \mathrm{M}(\mathrm{SE}=0.458 ; \mathrm{Cl}: \\
0.835-3.45)\end{array}$ \\
\hline ECG & $\begin{array}{l}0.0988 \mu \mathrm{M}(\mathrm{SE}=0.0442 ; \mathrm{Cl}: \\
0.0318-0.275)\end{array}$ & $\begin{array}{l}0.537 \mu \mathrm{M}(\mathrm{SE}=0.0946 ; \mathrm{Cl}: \\
0.375-0.843)\end{array}$ & $\begin{array}{l}0.769 \mu \mathrm{M}(\mathrm{SE}=0.113 ; \mathrm{Cl}: \\
0.586-1.02)\end{array}$ & $\begin{array}{l}4.22 \mu \mathrm{M}(\mathrm{SE}= \\
2.16 ; \mathrm{Cl}: 1.26-13.78)\end{array}$ \\
\hline EGC & $\begin{array}{l}6.62 \mu \mathrm{M}(\mathrm{SE}=3.23 ; \mathrm{Cl}: \\
2.92-16.5)\end{array}$ & $\begin{array}{l}43.3 \mu \mathrm{M}(\mathrm{SE}=22.8 ; \mathrm{Cl}: \\
16.1-129)\end{array}$ & $\begin{array}{l}5.96 \mu \mathrm{M}(\mathrm{SE}=17.3 ; \mathrm{Cl}: \\
0.101-\text { Ind.) }\end{array}$ & $7.58 \mu \mathrm{M}(\mathrm{SE}=3.87 ; \mathrm{Cl}: 2.93-20.7)$ \\
\hline EC & $>500 \mu \mathrm{M}$ & $>500 \mu \mathrm{M}$ & $>500 \mu \mathrm{M}$ & $>500 \mu \mathrm{M}$ \\
\hline Cat & ca. $500 \mu \mathrm{M}$ & $>500 \mu \mathrm{M}$ & $>500 \mu \mathrm{M}$ & $>500 \mu \mathrm{M}$ \\
\hline GA & $>500 \mu \mathrm{M}$ & $>500 \mu \mathrm{M}$ & $>500 \mu \mathrm{M}$ & $>500 \mu \mathrm{M}$ \\
\hline$P G$ & $>500 \mu \mathrm{M}$ & $>500 \mu \mathrm{M}$ & $>500 \mu \mathrm{M}$ & $>500 \mu \mathrm{M}$ \\
\hline OG & $\begin{array}{l}3.08 \mu \mathrm{M}(\mathrm{SE}=0.611 ; \mathrm{Cl}: \\
2.59-6.35)\end{array}$ & $\begin{array}{l}10.3 \mu \mathrm{M}(\mathrm{SE}=6.41 ; \mathrm{Cl}: \\
3.18-40.1)\end{array}$ & $\begin{array}{l}13.4 \mu \mathrm{M}(\mathrm{SE}=6.02 ; \mathrm{Cl}: \\
\text { 5.34-38.5) }\end{array}$ & $80.6 \mu \mathrm{M}(\mathrm{SE}=33.9 ; \mathrm{Cl}: 34.8-405)$ \\
\hline DG & $\begin{array}{l}3.73 \mu \mathrm{M}(\mathrm{SE}=0.566 ; \mathrm{Cl}: \\
2.83-4.56)\end{array}$ & $\begin{array}{l}1.63 \mu \mathrm{M}(\mathrm{SE}=0.312 ; \mathrm{Cl}: \\
1.05-2.67)\end{array}$ & $\begin{array}{l}44.4 \mu \mathrm{M}(\mathrm{SE}=22.4 ; \mathrm{Cl}: \\
18.8-150)\end{array}$ & 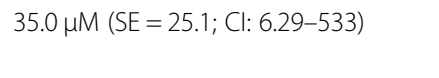 \\
\hline Myr & $\begin{array}{l}0.760 \mu \mathrm{M}(\mathrm{SE}=0.393 ; \mathrm{Cl}: \\
0.323-2.61)\end{array}$ & $\begin{array}{l}1.21 \mu \mathrm{M}(\mathrm{SE}=0.208 ; \mathrm{Cl}: \\
0.876-4.20)\end{array}$ & $\begin{array}{l}1.59 \mu \mathrm{M}(\mathrm{SE}=0.746 ; \mathrm{Cl}: \\
0.721-4.22)\end{array}$ & $0.721 \mu \mathrm{M}(\mathrm{SE}=0.497 ; \mathrm{Cl}: 0.177-2.68)$ \\
\hline DM & $\begin{array}{l}28.7 \mu \mathrm{M}(\mathrm{SE}=5.30 ; \mathrm{Cl}: \\
19.7-49.5)\end{array}$ & $\begin{array}{l}66.4 \mu \mathrm{M}(\mathrm{SE}=38.9 ; \mathrm{Cl}: \\
27.2-181)\end{array}$ & $\begin{array}{l}27.5 \mu \mathrm{M}(\mathrm{SE}=13.6 ; \mathrm{Cl}: \\
7.52-113)\end{array}$ & $14.3 \mu \mathrm{M}(\mathrm{SE}=3.14 ; \mathrm{Cl}: 5.93-22.2)$ \\
\hline
\end{tabular}

the process. The assays are straightforward to implement, reliable, robust, and quantitative. The approach can be readily adapted to addressing both overall and step-specific events in other ubiquitination and UBL post-translational modification cascades.

\section{Methods}

\section{Proteins and reagents}

All proteins were of human origin, except for RFC, which was from Saccharomyces cerevisiae, and were expressed and purified as previously described [19, 26-29], as detailed below. A sodium dodecyl sulfate (SDS)-polyacrylamide gel of representative protein preparations is shown in Additional file 8: Fig. S8. Biotinylated human ubiquitin was purchased from Boston Biochem/R\&D Systems (UB570). Purified pUC19 plasmid was nicked with Nt.BstNBI (New England Biolabs) at $55^{\circ} \mathrm{C}$ overnight. Streptavidin donor and anti-FLAG acceptor AlphaScreen beads were from PerkinElmer.

\section{His-tagged Uba1 preparation}

His-tagged human Uba1 in the pET3a bacterial expression vector (Addgene plasmid \#63571, courtesy of Titia Sixma) was expressed in Escherichia coli strain BL21-CodonPlus (DE3)-RIL (Agilent). The cells were centrifuged and washed in $1 \times$ phosphate-buffered saline (PBS). The cell suspensions were dropped into liquid nitrogen, and the resulting frozen beads were ground with a SPEX SamplePrep 6775 Freezer/Mill. The lysates were centrifuged, and the supernatant was applied to a $\mathrm{Ni}$-nitrilotriacetic acid (NTA) agarose (Machery-Nagel) column. Following repeated washings, the protein was eluted from the column with $250 \mathrm{mM}$ imidazole, then dialyzed against $20 \mathrm{mM}$ Tris- $\mathrm{HCl}, \mathrm{pH} 7.5,150 \mathrm{mM} \mathrm{NaCl}, 10 \%$ glycerol, 0.01\% NP40 , and $1 \mathrm{mM}$ freshly added dithiothreitol (DTT).

\section{Rad6-Rad18 dimer preparation}

Both human Rad6B and glutathione $S$-transferase (GST)fused human Rad18 constructs (each cloned into the pBJ842 yeast expression vector, which contains Leu and Trp auxotrophic markers) were introduced into the $S$. cerevisiae BJ5654 strain. The cells were grown in omission media (-Leu, -Trp), then collected when reaching an $\mathrm{OD}_{600}$ of $0.8-1$, centrifuged, and washed with $1 \times$ PBS. The cells were resuspended in yeast lysis buffer consisting of 50 $\mathrm{mM}$ HEPES, pH 7.5, $50 \mathrm{mM} \mathrm{KCl}, 300 \mathrm{mM} \mathrm{NaCl}, 10 \%$ sucrose, $0.5 \mathrm{mM}$ EDTA, and $2.8 \mathrm{mM} \beta$-mercaptoethanol). The cell lysate was then dropped into liquid nitrogen, then ground with a SPEX SamplePrep 6775 Freezer/Mill, collected into $1.5 \mathrm{ml}$ microcentrifuge tubes, and centrifuged. The supernatant was applied to a glutathione Sepharose $4 \mathrm{~B}$ (GE Healthcare) column, followed by repeated washing with $20 \mathrm{mM}$ Tris- $\mathrm{HCl}, \mathrm{pH} 7.5,10 \%$ glycerol, $0.01 \%$ NP-40, and $1 \mathrm{mM}$ DTT at progressively lower $\mathrm{NaCl}$ concentrations ( $3 \times 500 \mathrm{mM}, 3 \times 250 \mathrm{mM}, 1 \times 150 \mathrm{mM})$. The GST moiety was cleaved with PreScission Protease (GE Healthcare) with incubation for $2 \mathrm{~h}$ at $4{ }^{\circ} \mathrm{C}$ lightly on a shaker, and the dimer was eluted with a $1.5 \times$ bed volume equivalent of $20 \mathrm{mM}$ 
Tris-HCl, pH 7.5, $150 \mathrm{mM} \mathrm{NaCl}, 10 \%$ glycerol, $0.01 \%$ NP40 , and $1 \mathrm{mM} \mathrm{DTT}$.

\section{FLAG-tagged PCNA and FLAG-tagged Uba1 preparation} Constructs of human PCNA bearing GST and FLAG tags or human Uba1 bearing GST and FLAG tags, both cloned into the pBJ842 yeast expression vector, were used to prepare FLAG-tagged PCNA and FLAG-tagged Uba1 proteins, respectively, with subsequent expression in the S. cerevisiae BJ5654 strain and purification with cleavage of the GST moiety, as above.

\section{FLAG-tagged Rad6 and FLAG-tagged Rad18 preparation}

Constructs were generated with Gateway cloning technology (Life Technologies). Human Rad6B and human Rad18 cDNA sequences from entry constructs were recombined into a modified pGEX-6P-1 (Amersham) destination vector bearing GST and FLAG tags with a Gateway cassette via the LR Clonase II reaction (Invitrogen). Proteins were overexpressed in the E. coli strain BL21-CodonPlus (DE3)-RIL (Agilent). The proteins were purified with removal of the GST moiety, as above.

\section{RFC preparation}

The construct pLANT-2/RIL-RFC $\left[1^{\mathrm{s}}+5\right]$ was cotransformed with the construct pET(11a)-RFC[2+3+4] [26] into the E. coli strain BL21-CodonPlus (DE3)-RIL (Agilent), where $\mathrm{RFCl}^{\mathrm{s}}$ represents an $\mathrm{N}$-terminally truncated form of the large RFC subunit [30]. The cells were plated and allowed to grow under selection with ampicillin $(100 \mu \mathrm{g} / \mathrm{ml})$ and kanamycin $(50 \mu \mathrm{g} / \mathrm{ml})$ overnight. A single transformant colony was then picked and grown in $2 \mathrm{ml}$ of Luria-Bertani medium containing ampicillin $(100 \mu \mathrm{g} / \mathrm{ml})$ and kanamycin $(50 \mu \mathrm{g} / \mathrm{ml})$ at $37^{\circ} \mathrm{C}$ for $8 \mathrm{~h}$, then inoculated into a started culture of 21 of LuriaBertani medium containing ampicillin $(100 \mu \mathrm{g} / \mathrm{ml})$ and kanamycin $(50 \mu \mathrm{g} / \mathrm{ml})$ for $16 \mathrm{~h} .300 \mathrm{ml}$ of the starter culture was inoculated into 21 of Luria-Bertani medium and grown to an $\mathrm{OD}_{600}$ of 0.8 at $37^{\circ} \mathrm{C}$. The cultures were cooled down to $16^{\circ} \mathrm{C}$ and induced with $0.5 \mathrm{mM}$ isopropyl- $\beta$-D-thiogalactoside for $16 \mathrm{~h}$. All further steps were performed at $4{ }^{\circ} \mathrm{C}$.

The cells were harvested by centrifugation and then resuspended in HEG buffer (30 mM HEPES, pH 7.6, 0.5 mM EDTA, $10 \%$ glycerol, $5 \mathrm{mM} \beta$-mercaptoethanol) containing $150 \mathrm{mM} \mathrm{NaCl}$. To lyse the cells, lysozyme was added to $0.4 \mathrm{mg} / \mathrm{ml}$, and the cells were subjected to three freeze-thaw cycles, followed by mechanical shearing through a hypodermic needle. The cell lysate was treated with Benzonase endonuclease, purity grade II (Merck), according to the manufacturer's protocol. The cell lysate was clarified by centrifugation. RFC was purified by chromatography over an SP Sepharose column (bed volume of $6 \mathrm{ml}$ ), pre-equilibrated with HEG containing $50 \mathrm{mM} \mathrm{NaCl}$, followed by wash with $60 \mathrm{ml}$ of HEG buffer containing $50 \mathrm{mM} \mathrm{NaCl}$. Elution was carried with a gradient of $50-1000 \mathrm{mM} \mathrm{NaCl}$ in $60 \mathrm{ml}$ of HEG buffer. Peak fractions were collected, pooled, then diluted with Ni-NTA buffer ( $30 \mathrm{mM}$ HEPES, pH 7.6, 20 $\mathrm{mM}$ imidazole, $500 \mathrm{mM} \mathrm{NaCl}, 10 \%$ glycerol, $5 \mathrm{mM} \beta$ mercaptoethanol). The resulting sample was then applied to a Ni-NTA agarose (Machery-Nagel) column (bed volume of $500 \mu \mathrm{l}$ ), pre-equilibrated with Ni-NTA buffer. The column was then washed with $5 \mathrm{ml}$ of NiNTA buffer, and proteins were eluted by a three-step gradient (100 mM, $250 \mathrm{mM}$, and $500 \mathrm{mM}$ imidazole), each with $1.5 \mathrm{ml}$ overall volume. Fractions were tested for PCNA loading ability, and peak fractions were aliquoted, frozen in liquid $\mathrm{N}_{2}$, and stored at $-80^{\circ} \mathrm{C}$ until subsequent use.

\section{Alpha assay for PCNA ubiquitination}

Reactions were performed in 96-well white roundbottom polypropylene plates (Greiner Bio-One) in a buffer consisting of $40 \mathrm{mM}$ Tris- $\mathrm{HCl}, \mathrm{pH} 7.5,8 \mathrm{mM} \mathrm{MgCl}_{2}$, and $10 \%$ glycerol, with protein concentrations as noted below. Reactions were initiated with ATP added to a final concentration of $2 \mathrm{mM}$ (unless otherwise noted), with incubation for $2 \mathrm{~h}$ at $25^{\circ} \mathrm{C}$ (except for time-course experiments, where different incubation times were examined). The samples were then diluted in a buffer of $25 \mathrm{mM}$ HEPES, pH 7.5, $100 \mathrm{mM} \mathrm{NaCl}, 0.1 \%$ Tween 20, and $1 \mathrm{mM}$ DTT (Alpha buffer), containing $20 \mathrm{mM}$ EDTA and streptavidin donor and anti-FLAG AlphaScreen acceptor beads, under low-light conditions with dark yellow-green filter (LEE 090) covering sources of lighting. (In the case of time-course experiments, however, the EDTA, which terminates both the ATPdependent PCNA-loading process and the ubiquitination reaction cascade by chelating $\mathrm{Mg}^{2+}$, was instead added separately as a prior step until all samples were ready for Alpha detection.) In the case of the two-part assays involving quenching of Uba1 charging, EDTA was added to the Uba1 sample before the subsequent components and not with the donor and acceptor bead solution. Following incubation as indicated below, plates were read in a Tecan Spark plate reader (equipped with a dedicated high-energy laser light source and both cooling-and-heating temperature control for temperature consistency), with excitation at $680 \mathrm{~nm}$ and measurement of emission at $520-620 \mathrm{~nm}$, as appropriate for the AlphaScreen acceptor beads.

\section{FLAG-PCNA concentration variation in the PCNA ubiquitination assay}

Different FLAG-PCNA concentrations were tested with the other reaction components held constant at $2.5 \mathrm{nM}$ nicked pUC19, 50 nM RFC, 50 nM Uba1, 250 nM Rad6Rad18 dimer, and $250 \mathrm{nM}$ biotin-ubiquitin. The 
reactions were initiated by addition of ATP to $2 \mathrm{mM}$ for a final volume of $20 \mu \mathrm{l}$ with incubation for $2 \mathrm{~h}$ at $25^{\circ} \mathrm{C}$. (Note: The above conditions, serving as a starting point, are those we had previously optimized for virtually complete ubiquitination of PCNA as detected by Western blot analysis [19]). For the Alpha assay itself, the samples were diluted by a factor of $10 \times$ in Alpha buffer with donor and acceptor beads $(20 \mu \mathrm{g} / \mathrm{ml}$ each) and $20 \mathrm{mM}$ EDTA. Following incubation with beads for $1 \mathrm{~h}$ at $25^{\circ} \mathrm{C}$, plates were read in the plate reader (Fig. 2a).

\section{Biotin-ubiquitin concentration variation in the PCNA ubiquitination assay}

Different biotin-ubiquitin concentrations were tested with the other reaction components held constant at 2.5 nM nicked pUC19, $50 \mathrm{nM}$ RFC, $50 \mathrm{nM}$ Uba1, $250 \mathrm{nM}$ Rad6-Rad18 dimer, and 50 nM FLAG-PCNA, with the assay otherwise carried out as above (Fig. 2b).

\section{RFC concentration variation in the PCNA ubiquitination assay}

Different RFC concentrations were tested with the other reaction components held constant at $2.5 \mathrm{nM}$ nicked pUC19, 50 nM Uba1, 250 nM Rad6-Rad18 dimer, 50 nM FLAG-PCNA, and $250 \mathrm{nM}$ biotin-ubiquitin, with the assay carried out otherwise as above (Fig. 2c).

\section{Uba1 concentration variation in the PCNA ubiquitination assay}

Different Uba1 concentrations were tested with the other reaction components held constant at $2.5 \mathrm{nM}$ nicked pUC19, 50 nM RFC, 250 nM Rad6-Rad18 dimer, $50 \mathrm{nM}$ FLAG-PCNA, and $250 \mathrm{nM}$ biotin-ubiquitin, with the assay carried out otherwise as above (Fig. 2d).

\section{Rad6-Rad18 concentration variation in the PCNA ubiquitination assay}

Different Rad6-Rad18 dimer concentrations were tested with the other reaction components held constant at 2.5 nM nicked pUC19, $50 \mathrm{nM}$ RFC, $50 \mathrm{nM}$ Uba1, $250 \mathrm{nM}$ Rad6-Rad18 dimer, 50 nM FLAG-PCNA, and $250 \mathrm{nM}$ biotin-ubiquitin, with the assay carried out otherwise as above (Fig. 2e).

\section{Optimized protein concentrations for the PCNA ubiquitination cascade}

Based on the above experiments, we standardized on protein concentrations of $10 \mathrm{nM}$ RFC (though below optimal, we wished to lessen usage of the most onerous component of the system to express and purify), $10 \mathrm{nM}$ Uba1, 100 nM Rad6-Rad18 dimer, 50 nM FLAG-PCNA, and $250 \mathrm{nM}$ biotin-ubiquitin for the reaction component of the assay. The experiments below were thus conducted with these concentrations.
PCNA ubiquitination reaction volumes

Reactions were performed in different reaction volumes with incubation for $2 \mathrm{~h}$ at $25^{\circ} \mathrm{C}$, followed by Alpha detection after $10 \times$ dilution in Alpha buffer containing donor and acceptor beads $(20 \mu \mathrm{g} / \mathrm{ml}$ each $)$ and $20 \mathrm{mM}$ EDTA, and incubation in the dark for $4 \mathrm{~h}$ at $25^{\circ} \mathrm{C}$ prior to Alpha detection (Additional file 1: Fig. S1), as longer incubation time with beads resulted in improved signal (see Additional file 5: Fig. S5). Subsequent reactions were done in $20 \mu \mathrm{l}$, also with incubation in the dark for $4 \mathrm{~h}$ at $25^{\circ} \mathrm{C}$.

\section{Dilution factors for detection of ubiquitinated PCNA}

Reactions were diluted to different degrees in Alpha buffer containing donor and acceptor beads $(20 \mu \mathrm{g} / \mathrm{ml}$ each) and $20 \mathrm{mM}$ EDTA, with the assay otherwise carried out as above (Additional file 2: Fig. S2).

\section{Donor and acceptor bead concentrations for detection of ubiquitinated PCNA}

Reactions were diluted $10 \times$ in Alpha buffer with different equimolar donor and acceptor bead concentrations and $20 \mathrm{mM}$ EDTA, with the assay otherwise carried out as above (Additional file 3: Fig. S3a).

\section{Donor and acceptor bead ratios for detection of ubiquitinated PCNA}

Reactions were diluted $10 \times$ in Alpha buffer with different donor:acceptor bead concentration ratios and 20 $\mathrm{mM}$ EDTA, with the assay otherwise carried out as above (Additional file 3: Fig. S3b).

\section{Donor and acceptor bead order of addition for detection of ubiquitinated PCNA}

Reactions were diluted in stepwise fashion in equal volumes (for final dilution of $10 \times$ in Alpha buffer with donor and acceptor beads at $10 \mu \mathrm{g} / \mathrm{ml}$ final concentration for each), as follows: (1) donor beads first (with incubation for $2 \mathrm{~h}$ ), then acceptor beads (with further incubation for $2 \mathrm{~h}$ ), or (2) acceptor beads first (with incubation for $2 \mathrm{~h}$ ), then donor beads (with further incubation for $2 \mathrm{~h}$ ), or (3) donor and acceptor beads added simultaneously (with incubation for 2 or $4 \mathrm{~h}$ ), all at $25^{\circ} \mathrm{C}$, followed by incubation and Alpha detection (Additional file 4: Fig. S4).

\section{Donor and acceptor bead incubation times for detection of ubiquitinated PCNA}

After reactions, samples were diluted by $10 \times$ in Alpha buffer containing donor and acceptor beads $(10 \mu \mathrm{g} / \mathrm{ml}$ each) for different lengths of time (30 $\mathrm{min}$ to $12 \mathrm{~h}$ ) before Alpha detection (Additional file 5: Fig. S5). 
Final optimized conditions for the PCNA ubiquitination cascade and Alpha detection

In the end, based on the sum of experimental results for conditions of both the PCNA ubiquitination reaction and the Alpha detection steps of the overall assay, the final conditions chosen to balance both optimal assaying and material usage concerns for the PCNA ubiquitination assay were: $2 \mathrm{nM}$ nicked pUC19 (we reduced the nicked pUC19 concentration to an even $2 \mathrm{nM}$, as the precise DNA concentration makes little difference to the reaction), $10 \mathrm{nM}$ RFC, $10 \mathrm{nM}$ Uba1, $100 \mathrm{nM}$ Rad6-Rad18 dimer, $50 \mathrm{nM}$ FLAG-PCNA, and $250 \mathrm{nM}$ biotin-ubiquitin; initiation with $2 \mathrm{mM}$ ATP; a reaction volume of $20 \mu \mathrm{l}$ in 96-well plates, with incubation for $2 \mathrm{~h}$ at $25^{\circ} \mathrm{C}$; dilution by a factor of $10 \times$ in Alpha buffer containing donor and acceptor beads $(10 \mu \mathrm{g} / \mathrm{ml}$ each) and $20 \mathrm{mM}$ EDTA, with incubation of $4 \mathrm{~h}$ in the dark at $25^{\circ} \mathrm{C}$, followed by Alpha detection. In 384-well plates (with a reaction volume of $10 \mu \mathrm{l}$, followed by $10 \times$ dilution and Alpha detection as above), the reaction also proceeded, but with less consistency.

\section{PCNA ubiquitination reaction kinetics under final optimized conditions}

Reactions were stopped at different time intervals from 0 to $6 \mathrm{~h}$ by adding EDTA to $20 \mathrm{mM}$ and saved until the Alpha detection step, at which point the samples were diluted $10 \times$ in Alpha buffer containing donor and acceptor beads $\left(10 \mu \mathrm{g} / \mathrm{ml}\right.$ each), incubated for $4 \mathrm{~h}$ at $25^{\circ} \mathrm{C}$ in the dark, and Alpha detection was carried out (Fig. 2f).

\section{Titration of the concentration of ATP in the PCNA ubiquitination cascade}

Reactions were incubated in the presence of different concentrations of ATP, with the assay carried out under final optimized conditions as above (Additional file 6: Fig. S6a).

\section{DMSO tolerance of the PCNA ubiquitination cascade}

Reactions were incubated in the presence of different concentrations of DMSO, with the assay carried out under final optimized conditions as above (Additional file 6: Fig. S6b).

\section{Alpha assay for Uba1 ubiquitin thioester formation}

Concentrations of FLAG-Uba1 with biotin-ubiquitin concentration held constant at $150 \mathrm{nM}$ (Fig. 3a) were varied, as were biotin-ubiquitin with FLAG-Uba1 concentration held constant at $50 \mathrm{nM}$ (Fig. 3b), under otherwise identical reaction and assay conditions in a buffer consisting of $40 \mathrm{mM}$ Tris- $\mathrm{HCl}, \mathrm{pH} 7.5,8 \mathrm{mM} \mathrm{MgCl}_{2}$, and $10 \%$ glycerol. The reactions were initiated by addition of ATP to $2 \mathrm{mM}$ for a final volume of $20 \mu \mathrm{l}$, then incubated for $30 \mathrm{~min}$ at $25^{\circ} \mathrm{C}$, with reaction termination and dilution (except for the omission of DTT), incubation, and Alpha detection carried out under final optimized conditions as above.

\section{Alpha assay for Rad6 ubiquitin thioester formation}

Concentrations of FLAG-Rad6 with biotin-ubiquitin held constant at $150 \mathrm{nM}$ (Fig. 3c) and biotin-ubiquitin with FLAG-Rad6 held constant at $50 \mathrm{nM}$ (Fig. 3d) were each separately varied, under otherwise identical reaction and assay conditions in a buffer of $40 \mathrm{mM}$ Tris$\mathrm{HCl}, \mathrm{pH} 7.5,8 \mathrm{mM} \mathrm{MgCl}_{2}$, and $10 \%$ glycerol. The Uba1 concentration was $50 \mathrm{nM}$ in these experiments. The reactions were initiated by the addition of $2 \mathrm{mM}$ ATP for a final volume of $20 \mu \mathrm{l}$, incubated for $30 \mathrm{~min}$ at $25^{\circ} \mathrm{C}$, with termination and dilution (except for the omission of DTT), incubation, and Alpha detection carried out under final optimized conditions as above.

Once satisfactory starting conditions were found, the overall reaction was then conducted in two separate steps, which allows for screening for direct inhibitors of Rad6 ubiquitin thioester formation whose mechanism is not just secondary to inhibition of Uba1 ubiquitin thioester formation (Additional file 7: Fig. S7a). For initial precharging of Uba1 with biotin-ubiquitin, $100 \mathrm{nM}$ Uba1 was combined with $300 \mathrm{nM}$ biotin-ubiquitin, with the reaction initiated by addition of ATP to $2 \mathrm{mM}$, followed by incubation for $30 \mathrm{~min}$ at $25^{\circ} \mathrm{C}$. The reaction sample was then combined with an equal volume of 100 nM FLAG-Rad6 (which can be preincubated with compounds for screening for direct Rad6 inhibitors), for final concentrations of $50 \mathrm{nM}$ Uba1, $150 \mathrm{nM}$ biotin-ubiquitin, and $50 \mathrm{nM}$ FLAG-Rad6, with a final volume of $20 \mu \mathrm{l}$. The mixture was incubated for another $30 \mathrm{~min}$ at $25^{\circ} \mathrm{C}$, with the remaining procedures as before. To prevent the possibility of further charging of Uba1 with biotinubiquitin before addition of Rad6, we performed an experiment where the Uba1 sample was quenched with EDTA prior to mixing with Rad6 (to a final EDTA concentration of $20 \mathrm{mM}$, a concentration which for some reason negatively affected the transthioesterification reaction despite this step of the cascade not requiring $\mathrm{Mg}^{2+}-\mathrm{ATP}$, as noted above), with protein concentrations and incubation times being the same (Additional File 7: Fig. S7a). Lower concentrations of ATP $(250 \mu \mathrm{M})$ and $\mathrm{MgCl}_{2}(500 \mu \mathrm{M})$, with varying concentrations of EDTA $(500 \mu \mathrm{M}-8 \mathrm{mM})$, were also examined, with other conditions being the same (Additional File 7: Fig. S7b).

\section{Alpha assay for Rad18 autoubiquitination}

Concentrations of FLAG-Rad18 with biotin-ubiquitin held constant at $150 \mathrm{nM}$ (Fig. 3f) and concentrations of biotin-ubiquitin with FLAG-Rad18 held constant at 50 nM (Fig. 3g) were each separately varied under otherwise identical reaction and assay conditions in a buffer of $40 \mathrm{mM}$ Tris- $\mathrm{HCl}, \mathrm{pH} 7.5,8 \mathrm{mM} \mathrm{MgCl}_{2}$, and $10 \%$ 
glycerol in a volume of $20 \mu \mathrm{l}$. Uba1 was held constant at $50 \mathrm{nM}$, and Rad6-Rad18 dimer was held at $100 \mathrm{nM}$. The reaction was incubated at $25^{\circ} \mathrm{C}$ for $1 \mathrm{~h}$ in Alpha buffer (which includes DTT in it) containing donor and acceptor beads at $10 \mu \mathrm{g} / \mathrm{ml}$ each, and the assay was carried out under final optimized conditions as above.

We applied this two-part procedure also to the Rad18 autoubiquitination assay, wherein we allowed for charging of $100 \mathrm{nM}$ Ubal and $200 \mathrm{nM}$ biotin-ubiquitin with $250 \mu \mathrm{M} \mathrm{ATP}$ and $500 \mu \mathrm{M} \mathrm{MgCl}_{2}$ for $30 \mathrm{~min}$ at $25^{\circ} \mathrm{C}$, then quenched the reaction by addition of EDTA to a final concentration of $1 \mathrm{mM}$. We mixed the sample with an equal volume of $200 \mathrm{nM}$ Rad6-Rad18 dimer and 100 or $200 \mathrm{nM}$ FLAG-Rad18, as indicated (for final protein concentrations of $50 \mathrm{nM}$ Uba1, $100 \mathrm{nM}$ biotin-ubiquitin, 100 nM Rad6-Rad18 dimer, and 50 or 100 nM FLAGRad18), then incubated for an additional $1 \mathrm{~h}$ at $25^{\circ} \mathrm{C}$ in Alpha buffer containing donor and acceptor beads at $10 \mu \mathrm{g} / \mathrm{ml}$ each and $20 \mathrm{mM}$ EDTA, and the assay was then carried out under final optimized conditions as above (Additional file 7: Fig. S7c).

\section{Testing of previously identified inhibitors of ubiquitination in the Alpha assay}

We employed the above optimized conditions and examined the effect of green tea compounds that we previously identified as inhibitors of ubiquitination at the level of Uba1 [19]. Compounds were added to wells in 96-well plates containing all the components of the reaction except for ATP, with preincubation for $15 \mathrm{~min}$. ATP was then added to $2 \mathrm{mM}$ to initiate the ubiquitination cascade with a final volume of $20 \mu \mathrm{l}$, and the procedures for reaction and Alpha assay were the optimized ones described above (Fig. 6). We also conducted Alpha assays for Uba1 ubiquitin thioester formation, with preincubation for 15 min with the compounds prior to initiation of reaction and assay, as described above (Fig. 7a and b).

\section{Statistical analysis}

Statistical analysis was performed with Microsoft Excel and GraphPad Prism 8 software.

\section{Supplementary information}

Supplementary information accompanies this paper at https://doi.org/10. 1186/s12860-020-00262-5

Additional file 1: Figure S1. PCNA ubiquitination reaction volumes. PCNA ubiquitination was conducted in different volumes, followed by incubation in Alpha buffer with donor and acceptor beads and detection. Data represent mean and SD for 8 samples. For conditions and procedures for this and subsequent figures, see Methods.

Additional file 2: Figure S2. Dilution factors for detection of ubiquitinated PCNA. PCNA ubiquitination reactions were diluted to different degrees as indicated in Alpha buffer with donor and acceptor beads, followed by incubation and detection. Data represent mean and
SD for $\geq 3$ samples. Top and bottom panels represent two separate experiments with different ranges of dilution.

Additional file 3: Figure S3. Alpha donor and acceptor bead concentrations and ratios for detection of ubiquitinated PCNA. a Concentrations of donor and acceptor beads were varied, as indicated, followed by incubation and detection. Data represent mean and SD for 4 samples $\mathbf{b}$ Ratios of donor and acceptor beads (values in $\mu \mathrm{g} / \mathrm{ml}$ ) were varied, followed by incubation and detection. Data represent mean and SD for 7-8 samples. $D=$ donor beads; $A$ = acceptor beads.

Additional file 4: Figure S4. Donor and acceptor bead order of addition for detection of ubiquitinated PCNA. The order of addition of Alpha donor and acceptor beads was examined, with incubation for $2 \mathrm{~h}$ with one and then further for $2 \mathrm{~h}$ after addition of the other (compared to simultaneous addition and incubation for $2 \mathrm{~h}$ or $4 \mathrm{~h}$ ), followed by detection. Data represent mean and SD for 3 samples. $D=$ donor beads; A = acceptor beads.

Additional file 5: Figure S5. Donor and acceptor bead incubation times for detection of ubiquitinated PCNA. Times of incubation with beads prior to Alpha detection were evaluated. Data represent mean and SD for 3 samples. a Incubation time course with donor and acceptor bead concentrations at $20 \mu \mathrm{g} / \mathrm{ml}$ each. b Incubation time course with donor and acceptor bead concentrations at $10 \mu \mathrm{g} / \mathrm{ml}$ each for Alpha detection after PCNA ubiquitination reaction in the presence and absence of ATP, the latter to test whether any non-specific precipitation or other effects would by themselves influence subsequent signal over time. $\mathrm{D}=$ donor beads; $\mathrm{A}$ = acceptor beads.

Additional file 6: Figure S6. Variation of ATP concentration and DMSO tolerance in Alpha assay for PCNA ubiquitination. a ATP concentrations for the PCNA ubiquitination cascade were varied, followed by incubation and detection. Data represent mean and SD for 3 samples. b Different concentrations of DMSO were added to the reactions, followed by incubation and detection. Data represent mean and SD for 3 samples.

Additional file 7: Figure S7. a Split two-part Rad6 ubiquitin thioester formation assay, with precharging of Uba1 with biotin-ubiquitin prior to addition of Rad6 and quenching of Uba1 charging with EDTA to a final concentration of $20 \mathrm{mM}$ (added between steps to chelate $\mathrm{Mg}^{2+}$ and prevent further ATP-dependent Uba1 charging with ubiquitin); negative control was without ATP, while the positive control and EDTA-treated samples included ATP. Data represent mean and SD for 8 samples. b Modified two-part Rad6 ubiquitin thioester formation assay reaction with $250 \mu \mathrm{M}$ ATP and $500 \mu \mathrm{M} \mathrm{MgCl}_{2}$, with Uba1 quenching with varying concentrations of EDTA. Data represent mean and SD for 3 samples. c Two-part Rad18 autoubiquitination assay with $250 \mu \mathrm{M}$ ATP and $500 \mu \mathrm{M}$ $\mathrm{MgCl}_{2}$, with Uba1 charging quenched by adding EDTA to $1 \mathrm{mM}$, followed by addition of $100 \mathrm{nM}$ Rad6-Rad18 dimer and $50 \mathrm{nM}$ or $100 \mathrm{nM}$ FLAGRad18. Data represent mean and SD for 4 samples.

Additional file 8: Figure S8. SDS-polyacrylamide gel of proteins used in this study. Proteins were resolved on a 12\% SDS-polyacrylamide gel and stained with Coomassie Brilliant Blue R-250. Each lane represents a different protein preparation, and the relevant protein bands are indicated with arrow marks. Note: The 5 subunits of S. cerevisae RFC were only resolved into 3 bands, since the molecular weights of the larger of the three of the smaller subunits are so close to each other.

\section{Abbreviations}

Alpha: Amplified luminescent proximity homogeneous assay; $\mathrm{Cl}$ : Confidence interval; DMSO: Dimethyl sulfoxide; DTT: Dithiothreitol; E1: Ubiquitinactivating enzyme; E2: Ubiquitin-conjugating enzyme; E3: Ubiquitin ligase; EDTA: Ethylenediaminetetraacetic acid; ELISA: Enzyme-linked immunosorbent assay; GST: Glutathione S-transferase; $I_{50}$ : Half-maximal inhibitory concentration; NTA: Nitrilotriacetic acid; $\mathrm{OD}_{600}$ : Optical density at $600 \mathrm{~nm}$; PBS: Phosphate-buffered saline; PCNA: Proliferating cell nuclear antigen; RET: Resonance energy transfer; RFC: Replication factor C; SD: Standard deviation; SE: Standard error; SDS: Sodium dodecyl sulfate; TLS: Translesion DNA synthesis; UBL: Ubiquitin-like protein 


\section{Acknowledgements}

We thank Katalin Kovács, Katalin Kontár, and Péter Germán for technical assistance.

\section{Authors' contributions}

GF and LH conceived the project. PG and GS performed the experiments. LP purified RFC protein and EK made new DNA constructs for this study. GF, PG, and GS analyzed the data. GF was the main contributor in writing the manuscript. All authors read and approved the final manuscript.

\section{Funding}

This work was supported by the National Research, Development and Innovation Office (GINOP-2.3.2-15-2016-00020 and GINOP-2.3.2-15-201600026). This project has also received funding from the European Union's Horizon 2020 research and innovation programme under grant agreement No. 739593. The funding bodies played no role in the design of the study, collection, analysis, interpretation of data, or writing of the manuscript.

\section{Availability of data and materials}

Data and materials used in the current study are available from the corresponding authors on request.

\section{Ethics approval and consent to participate}

Not applicable.

\section{Consent for publication}

Not applicable.

\section{Competing interests}

The authors declare that they have no competing interests.

\section{Author details}

${ }^{1}$ HCEMM-BRC Mutagenesis and Carcinogenesis Research Group, Institute of Genetics, Biological Research Centre, Szeged, Temesvári krt. 62, Szeged 6726, Hungary. ${ }^{2}$ Doctoral School of Biology, Faculty of Science and Informatics, University of Szeged, Közép fasor 52, Szeged 6726, Hungary. ${ }^{3}$ Visal Plus Ltd., Temesvári krt. 62, Szeged 6726, Hungary.

\section{Received: 22 October 2019 Accepted: 12 March 2020}

Published online: 30 March 2020

\section{References}

1. Knobel PA, Marti TM. Translesion DNA synthesis in the context of cancer research. Cancer Cell Int. 2011;11:39.

2. Sharma S, Helchowski CM, Canman CE. The roles of DNA polymerase $\zeta$ and the $Y$ family DNA polymerases in promoting or preventing genome instability. Mutat Res. 2013;743-744:97-110.

3. Korzhnev DM, Hadden MK. Targeting the translesion synthesis pathway for the development of anti-cancer chemotherapeutics. J Med Chem. 2016;59: 9321-36.

4. Jansen JG, Tsaalbi-Shtylik A, de Wind N. Roles of mutagenic translesion synthesis in mammalian genome stability, health and disease. DNA Repair (Amst). 2015;29:56-64.

5. Zafar MK, Eoff RL. Translesion DNA synthesis in cancer: molecular mechanisms and therapeutic opportunities. Chem Res Toxicol. 2017;30: 1942-55.

6. Yang Y, Gao Y, Zlatanou A, Tateishi S, Yurchenko V, Rogozin IB, et al. Diverse roles of RAD18 and Y-family DNA polymerases in tumorigenesis. Cell Cycle. 2018;17:833-43.

7. Dieckman LM, Freudenthal BD, Washington MT. PCNA structure and function: insights from structures of PCNA complexes and posttranslationally modified PCNA. Subcell Biochem. 2012;62:281-99.

8. Choe KN, Moldovan GL. Forging ahead through darkness: PCNA, still the principal conductor at the replication fork. Mol Cell. 2017;65:380-92.

9. Slade D. Maneuvers on PCNA rings during DNA replication and repair. Genes (Basel).

10. Kanao R, Masutani C. Regulation of DNA damage tolerance in mammalian cells by post-translational modifications of PCNA. Mutat Res. 2017;803-805: 82-8.
11. Leung W, Baxley R, Moldovan G-L, Bielinsky A-K. Mechanisms of DNA damage tolerance: Post-translational regulation of PCNA. Genes (Basel). 2018;10:10.

12. Miyase S, Tateishi S, Watanabe K, Tomita K, Suzuki K, Inoue H, et al. Differential regulation of Rad18 through Rad6-dependent mono- and polyubiquitination. J Biol Chem. 2005;280:515-24.

13. Zeman MK, Lin JR, Freire R, Cimprich KA. DNA damage-specific deubiquitination regulates Rad18 functions to suppress mutagenesis. J Cell Biol. 2014;206:183-97.

14. Dove KK, Klevit RE. RING-between-RING E3 ligases: emerging themes amid the variations. J Mol Biol. 2017:429:3363-75.

15. Zheng N, Shabek N. Ubiquitin ligases: structure, function, and regulation. Annu Rev Biochem. 2017;86:129-57.

16. Walden $H$, Rittinger K. RBR ligase-mediated ubiquitin transfer: a tale with many twists and turns. Nat Struct Mol Biol. 2018;25:440-5.

17. Weber J, Polo S, Maspero E. HECT E3 ligases: a tale with multiple facets. Front Physiol. 2019;10:370.

18. Eglen RM, Reisine T, Roby P, Rouleau N, Illy C, Bossé R, et al. The use of AlphaScreen technology in HTS: current status. Curr Chem Genomics. 2008; 1:2-10.

19. Fenteany $G$, Gaur P, Hegedűs L, Dudás K, Kiss E, Wéber E, et al. Multilevel structure-activity profiling reveals multiple green tea compound families that each modulate ubiquitin-activating enzyme and ubiquitination by a distinct mechanism. Sci Rep. 2019;9:12801.

20. Kus B, Gajadhar A, Stanger K, Cho R, Sun W, Rouleau N, et al. A high throughput screen to identify substrates for the ubiquitin ligase Rsp5. J Biol Chem. 2005;280:29470-8

21. Rouleau N, Wang J, Karras L, Andrews E, Bielefeld-Sevigny M, Chen Y. Highly sensitive assays for SUMOylation and small ubiquitin-like modifierdependent protein-protein interactions. Anal Biochem. 2008;375:364-6.

22. Takahashi H, Nozawa A, Seki M, Shinozaki K, Endo Y, Sawasaki T. A simple and high-sensitivity method for analysis of ubiquitination and polyubiquitination based on wheat cell-free protein synthesis. BMC Plant Biol. 2009;9:39.

23. Schneider S, Chen H, Tang J, Emkey R, Andrews PS. Development of a homogeneous AlphaLISA ubiquitination assay using ubiquitin binding matrices as universal components for the detection of ubiquitinated proteins. Biochim Biophys Acta, Mol Cell Res. 2012;1823:2038-45.

24. Yan Z-H, Burkhardt A, Loke H-K, Chen J, Xu Q, Brauer P, et al. Quantifiable analysis of cellular pathway inhibition of a Nedd8-activating enzyme inhibitor, MLN4924, using AlphaScreen. Anal Biochem. 2013;439:109-15.

25. Li YJ, Du L, Wang J, Vega R, Lee TD, Miao Y, et al. Allosteric inhibition of ubiquitin-like modifications by a class of inhibitor of SUMO-activating enzyme. Cell Chem Biol. 2019;26:278-288.e6.

26. Finkelstein J, Antony E, Hingorani MM, O'Donnell M. Overproduction and analysis of eukaryotic multiprotein complexes in Escherichia coli using a dual-vector strategy. Anal Biochem. 2003;319:78-87.

27. Haracska L, Unk I, Prakash L, Prakash S. Ubiquitylation of yeast proliferating cell nuclear antigen and its implications for translesion DNA synthesis. Proc Natl Acad Sci U S A. 2006;103:6477-82.

28. Unk I, Hajdú I, Fátyol K, Hurwitz J, Yoon J-H, Prakash L, et al. Human HLTF functions as a ubiquitin ligase for proliferating cell nuclear antigen polyubiquitination. Proc Natl Acad Sci U S A. 2008;105:3768-73.

29. Juhasz S, Balogh D, Hajdu I, Burkovics P, Villamil MA, Zhuang Z, et al. Characterization of human Spartan/C1orf124, an ubiquitin-PCNA interacting regulator of DNA damage tolerance. Nucleic Acids Res. 2012;40:10795-808.

30. Gomes XV, Gary SL, Burgers PM. Overproduction in Escherichia coli and characterization of yeast replication factor C lacking the ligase homology domain. J Biol Chem. 2000;275:14541-9.

\section{Publisher's Note}

Springer Nature remains neutral with regard to jurisdictional claims in published maps and institutional affiliations. 